\title{
On Contents and Characteristics of Lake Environmental Accounting Elements
}

\author{
Yanli Li \\ Department of Management \\ Guilin University of Technology, GLUT \\ Guilin, China \\ lylay@126.com
}

\begin{abstract}
Lakes are important natural resources in our country. Due to the expansion of the human economic activities, the lake resources increasingly decrease, and the lake environment is deteriorating. The lake management needs introducing the accounting information for response and supervision. This paper researches the contents and characteristics of the lake environmental accounting elements from the perspective of the region, holds that the lake environmental elements should contain the environmental assets, environmental liabilities, environmental rights and interests, environmental expenses, environmental benefits and environmental profits, and possesses the characteristics of the environmental matters differing from the traditional financial accounting.
\end{abstract}

Keywords-Lake; environmental accounting; elements; contents; characteristics

\section{INTRODUCTION}

In China, the ownership of the natural resources belongs to the country. As the macro controller, the country should perform the responsibilities of the environmental management. It requires the government departments seize the consumption and stock value of the natural resources, the environmental losses, and the expenditures for the purpose of protecting the environmental resources from an overall perspective. Mesoscopic environmental accounting refines a country into some area, such as researching only in allusion to the lakes or forests in some area, and the balance accounting of the gross natural resources in some area from the perspective of the whole society and at the height of the sustainable development, which is more beneficial to supervising the usage and compensation of a certain specific environmental resource, maintaining the ownership quantity of the environmental assets, and also can provide the information for the macroscopic accounting. Lake environmental accounting is to compute the environment from the perspective of the lake areas, so as to realize the sustainable development of the lake resources.

\section{NECESSITY OF BUILDING THE LAKE ENVIRONMENTAL ACCOUNTING}

Our country possesses numerous lakes, including 2,848 lakes with the area of more than $1 \mathrm{~km} 2$. The total area of the lakes is $80,645 \mathrm{~km} 2$, accounting for about $0.8 \%$ of the national land area. The lake is the base for human habitat, and the important available surface water resource with the multifunction. With the progress of science and technology, the relationship between human and the lake environment has developed into the initiative transformation from the passive adaptation development. Since 20th century, the impact of the ever increasing population and the development of the industrialization and urbanization on the lake environment had surpassed the self-adjusting ability of the lake system. The enrichment of the nutrient substances $(\mathrm{N}, \mathrm{P})$ arising out of the domestic wastewater and industrial and agricultural pollutions and the water overuse are leading to the deterioration of the lake ecological environment, and had endangered the survival environment of the lake regions and the sustainable development of the social economy. In the past 50 years, nearly thousands of natural lakes had disappeared in our country, with 20 lakes annually on average, which had caused the enormous influences for the natural environment in China. Since the pollution incident of the Songhua River at the end of 2005, more than 140 water pollution accidents occurred in China, with an accident every 2 or 3 days on average. The outbreak of the blue- green algae in Taihu Lake at the end of May 2007 set off an alarm for humans once again. With the deterioration of the lake environmental problems in various regions, the Chinese government should input large sums of money to govern the lake environment every year. However, the lake pollution incidents continued after governing repeatedly, which produced tremendous inconvenience for people's life, and caused the huge losses economically. On the one hand, people utilize the lake resources to develop the economy and gain the earnings. On the other hand, people take a huge toll for maintaining the normal environmental effect of the lakes. So how much do the lakes bring the earnings for humans? How many costs should people pay for maintaining the environmental effect of lakes? Is human beneficiary or victim in the lake environment and the economic development? Here it is necessary to introduce the accounting information for response, and meanwhile the environmental accounting is needed for supervising the economic activities of humans in the future. It is necessary to incorporate the natural resources and environmental conditions into the financial accounting, and fully reflect the interaction effect between the production and operation of humans and the environment by the specific accounting method, to prevent the economic development phenomenon with sacrificing the resources as the cost from emerging constantly, so as to supervise the environmental protection of the lakes. 


\section{Contents of LAKE ENVIRONMENTAL ACCOUNTING ELEMENTS}

The accounting elements are the specific contents of the financial accounting and supervision, and constitute the basic framework structure of the accounting statement. As for the environmental accounting elements, there are various different opinions in the theoretical circle. (1) For theory of three elements, it holds that the environmental accounting elements include the environmental assets, environmental liabilities and environmental cost, or environmental assets, environmental expenses and environmental benefits, or environmental cost, environmental incomes and environmental accounting incomes (2) For theory of four elements, it holds that the environmental accounting elements include the environmental assets, environmental liabilities, environmental expenditures and environmental incomes, or environmental value, environmental cost, environmental incomes and environmental profits. (3) For theory of five elements, it holds that the environmental accounting elements include the environmental assets, environmental liabilities, environmental capital, environmental expenses and environmental benefits. (4) For theory of six elements, it holds that the environmental accounting elements include the environmental assets, environmental liabilities, environmental rights and interests, environmental incomes, environmental expenses and environmental profits. From the perspective of the lake environmental accounting, "theory of three elements" is not comprehensive enough, or does not consider the incomes of the environmental resources for the government, or does not consider the possible liabilities of the government departments in the environmental activities, or does not consider the existence of environmental resources as the assets. "Theory of four elements" does not have the account environmental rights and interests corresponding to the environmental assets, and is detrimental to the needs of double entry. "Theory of five elements" does not match the expenses and benefits, and is detrimental to understanding the final results arising out of managing and protecting the environment by the information user. The basic thoughts of "theory of six elements" is to determine the environmental accounting elements in accordance with the traditional accounting elements, with the purpose of pursuing the integrity of the environmental accounting theoretical system and paying attention to the connection and coordination between the environmental accounting and traditional financial accounting. Moreover, six elements of accounting are widely acknowledged internationally. In case of regarding the environmental accounting as an independent branch of accountancy, rather than the accessory of the traditional financial accounting, six elements possess the best integrity and independence, and enable the environmental accounting to comprehensively and independently reflect the environmental contents and provide the relevant environmental information.

The lake environmental accounting element is the further classification of the lake environmental accounting object. The lake environmental accounting object should include the ownership of the lake resources that the accounting subject occupies or uses and the resources, the environmental benefits arising out of utilizing the lake resources by the accounting subject and the generated expenses, and the liabilities due to collecting the environmental protection expenses of the enterprises. Meanwhile, the environmental accounting objective is to provide the useful information for the information user, while the carrier of the information expression is the environmental accounting statement. The environmental accounting statement includes the balance sheet, profit statement, and cash flow statement etc. Therefore, the classification of the accounting object also constitutes the classification of the accounting statement elements. According to the specific contents of the lake environmental accounting object and the requirements for the user of environmental accounting information, the lake environmental accounting elements should be identified as six categories, involving environmental assets, environmental liabilities, environmental rights and interests, environmental benefits, environmental expenses and environmental profits. The lake environmental accounting elements should be consistent with the financial accounting elements in numbers, but should be different from the financial accounting elements in contents, which possess the characteristics of the lake environmental matters.

\section{CHARACTERISTICS OF LAKE ENVIRONMENTAL ACCOUNTING ELEMENTS}

\section{A. Characteristics of lake environmental assets}

Firstly, the development and utilization of the lake environmental assets are irreversible. In other words, it is infeasible technically to change the present situations to recover the underdeveloped status after the behavior of developing and utilizing the lake resources destroys the original conditions, or it must go through a considerable length of time. Next, the variation of the lake environmental assets conforms to the ecological balance mechanism. The lake resource consumption within certain limits may be compensated through the self-adjusting function and regeneration function of the lake ecological resource system. In case of failing to conform to the balance rules, it will result in the degradation and unbalance of the lake ecosystem. Finally, the lake environmental assets possess the scarcity. With the population explosion and the rapid economic development, humans have larger and larger requisite amounts for the lake resources, and go far beyond their own renewability. In addition, humans discharge more and more wastes into the lakes, which exceed the endurance of the environmental capacity, to make the lake areas reduce continuously and the cleanliness of the existing lake resources lower continuously, and make it possess the scarcity.

\section{B. Characteristics of lake environmental liabilities}

The excessive consumption of the environmental assets is actually the consumption of the assets of descendants and constitutes the liabilities for the descendants. The environmental liabilities as said in the environmental economics mean the responsibilities of the contemporaries for the next generation for the purpose of guaranteeing the hedge of the environmental assets, and the "intergenerational debt" of the contemporaries for humans in the aspect of the environmental resources in the future. When the production and operation activities of humans excessively consume or 
pollute the lake resources, the subject of liability should take the definite toll as the future expenditure of repairing the lake environment. The lake environmental liabilities mean the direct liabilities for purifying the environment and various predicted expenditures for purifying the environment. The enterprise is the user and polluter of the environmental resources, and the true undertaker of the environmental liabilities. The environmental accounting subject collects the payable expenses of the responsible enterprise and various expenses relevant to the usage of environmental resources and environmental protection as the future expenditures of protecting the lake environment, accordingly forming the liabilities. While disposing the business, the lake environmental accounting subject conducts the disposal of accounts receivables for the payable expenses of the enterprise, but these accounts receivables definitely can not be regarded as the incomes of the accounting subject. In case of acting as the incomes, more incomes will be better, i.e. greater destructions of the enterprise for the environment will be better, which violates the purpose of the environmental accounting. Introducing the concept of the environmental liabilities into the lake environmental accounting system is to warn that the human environmental resources are limited, and it is necessary to use the environmental resources reasonably and moderately.

\section{Characteristics of lake environmental rights and interests}

Most lake environmental assets are acquired for free. Even some environmental assets are acquired at a price, and the price is difficult to reflect the values of the environmental assets, not to mentioning the existence of the rights and interests corresponding to the assets. However, from the requirements of the double entry, it can reflect the value and structure of the environmental assets by the environmental capital, and reflect the environmental capital is deemed as a capital corresponding to the physical capital and human capital. Thus, the environmental asset is equal to the environmental capital. Moreover, when the water resource quality of lakes upgrades after governing, or the value of the water resources increases arising out of the change for the selected elements of the water resource value by the fuzzy mathematics, it can be reflected through the capital reserve subject. The capital reserve and environmental capital belong to the account of the environmental rights and interests. Thus, we can set the environmental capital and capital reserve as the subsidiary accounts, and meanwhile set up the general ledger account for the general classified accounting of the environmental rights and interests. The lake environmental rights and interests mean the rights and interests of the country for the lake environmental assets, and are the economic benefits which the country enjoys in the lake environmental assets. The measurement method of the lake environmental rights and interests is the same as that of the ownership interests of the enterprise. In the traditional accounting, the amount of the ownership interests of the enterprise depends on the measurement of the assets and liabilities. Ownership interests = assets - liabilities. Basically, the special measurement problems do not exist. The lake environmental rights and interests are just the result of some mathematical operation, which is an equilibrium number. Environmental rights and interests $=$ environmental assets - environmental liabilities. It can only be made through the measurement of the corresponding environmental assets and environmental liabilities indirectly.

\section{Characteristics of lake environmental benefits}

In the modern Chinese dictionary, the meaning of incomes is the incomes in the production or business, and the benefit means the effect and interest. The lake resources bring the incomes for humans after utilizing them for production, and also provide the indirect ecological benefits which embody the effect and interest from the existence of the lake resources for humans. Therefore, the direct benefits and indirect benefits from the relevant lake resources are reflected by "environmental benefits" rather than "environmental revenues". The increase of the environmental benefits does not have the necessary link with the increase of the environmental assets. On contrary, the generation of the environmental benefits is always accompanied by the reduction of the environmental assets. When the lakes are used for irrigation, the generated environmental benefits are at the cost of the depletion of the lake environmental asset value. In addition, even if the environmental asset value is not changed, it may generate the environmental benefits, such as the ecological benefits because the lake regulates the climate, beautifies the environment, and reproduces the biological diversity.

\section{E. Characteristics of lake environmental expenses}

The generation of the environmental expenses is always accompanied by the decrease of the environmental assets, and sometimes it is reflected as the decrease of the physical assets in the socioeconomic system. For example, the depletion expenses of the lake resources are directly manifested as the reduction of the lake environmental asset value, and the protection expenses of the lake resources are directly manifested as the reduction of the physical assets in the socioeconomic system. In addition, the scale of the lake environmental expenses has the trend to expand gradually. With the expansion of the production scale, the depletion of the lake resources reserve is aggravated, to increase the depletion expenses of the lake resources. In order to achieve the sustainable development, the basic stock expenses of maintaining the lake resources must be increased. On the other hand, the discharge of the wastes exceeds the limit of the environmental capacity, to increase the degradation expenses of the lake ecological resources. In order to protect and improve the lake environment, it is bound to increase the protection expenses of the ecological resources. Therefore, with the expansion of the production scale and the increase of the population, it is necessary to increase the lake environmental expenses accordingly. The lake environmental expenses have the trend to expand gradually.

\section{F. Characteristics of lake environmental profits}

Firstly, the lake environmental profit reflects the results of the lake manager representing the country for managing the lakes, and also reflects the degree of the sustainable development for the lake resources. The lake manager should regard obtaining the environmental profits as the basic purpose of management. However, the lake environmental management 
finally acquires the social benefits, so the lake profits may be the negative number, expressing the net loss. At the initial stage of protecting and governing the lakes, the lake environmental profits are always the negative numbers. With the gradual control of the lake pollution and the increasingly beautified lake environment, the benefits acquired from the lake environment will be more than the expenditures gradually, accordingly gaining the lake profits. Next, in the accounting standard issued in 2006, the matching principle would not be emphasized as the basic principle, mainly because the matching between the incomes and expenses in the narrow sense has some difficulties, and it lays stress on matching between the incomes and expenses in the broad sense, accordingly generating the profits. In the lake environmental accounting, the direct matching relations between the environmental expenses and environmental benefits do not exist. For example, the losses arising out of the quality reduction of the ecological resources due to the discharge of wastes exceeding the lake environmental capacity will not be compensated by the corresponding earnings. For another example, the generation of the lake ecological benefits is its own function of the lake, without needing any cost. However, from the perspective of the sustainable development, the generation of the environmental expenses is to maintain and increase the environmental benefits which the lakes can provide. Therefore, in the lake environmental accounting, both of them are matched, accordingly generating the environmental profits, which reflect the result of managing the environment by the environmental manager and the benefits of the environmental resources for humans.

\section{CONCLUSION}

In the lake environmental accounting elements, there are many fuzzy phenomena, such as fuzziness of lake resource utility, fuzziness of lake resource scarcity, and fuzziness of balance etc. If emphasizing the accuracy of the measurement method, it will have the conflict with the complexity of the things. When the complexity exceeds some limits, the fuzziness can not be ignored. When the accounting data do not have the important errors or deviations and can truthfully reflect the situations to be reflected or which should be reflected, accordingly for the decision-making basis of the user of the accounting information, the accounting data will possess the reliability. Due to the limitation of the accounting measurement method and reflection technology and the complexity of the lake resources, the reflected fact will have the characteristics of fuzziness. It does not belong to the deviation, but it still can be considered as possessing the reliability. When the lake resources are acquired at a cost, the value can be measured as per the cost. When the lake resources are granted by the nature, it can be measured on basis of the reasonable estimation. It can be measured in accordance with the estimated results provided the estimation possesses the reasonableness.

\section{REFERENCES}

[1] Hong Xu. Research for Environmental Accounting Theory and Practice [M]. Beijing: China(In Chinese)

[2] Yu Xiaolei. The New Enterprise Accounting Principle Practice Guideline and Explanation[M]. Beijing: China Machine Press, 2006(In Chinese).

[3] Zhu xueyi. Intermediate Financial Accounting[M]. Beijing: China Machine Press, 2007(In Chinese).

[4] Chen Jingfeng, Liu Zhigang. Exploration of Element Affirmation and Calculation in Environmental Accounting [J]. Forestry Finance and Accounting, 2005(4):14-15(In Chinese). 